\title{
Bone Response to a Ca- and P-Enriched Titanium Surface Obtained by Anodization
}

\author{
Rosemeire de Lordo FRANCO ${ }^{1}$ \\ Roberto CHIESA ${ }^{2}$ \\ Paulo Tambasco de OLIVEIRA ${ }^{1}$ \\ Marcio Mateus BELOTI ${ }^{1}$ \\ Adalberto Luiz ROSA ${ }^{1}$ \\ ${ }^{1}$ Cell Culture Laboratory, School of Dentistry of Ribeirão Preto, University of São Paulo, Brazil
${ }^{2}$ Department of Chemistry, Materials, and Chemical Engineering "G. Natta”, Polytechinic of Milan, Milan, Italy
}

This study evaluated bone response to a Ca- and P- enriched titanium (Ti) surface treated by a multiphase anodic spark deposition coating (BSP-AK). Two mongrel dogs received bilateral implantation of 3 Ti cylinders $(4.1 \mathrm{x} 12 \mathrm{~mm})$ in the humerus, being either BSPAK treated or untreated (machined - control). At 8 weeks postimplantation, bone fragments containing the implants were harvested and processed for histologic and histomorphometric analyses. Bone formation was observed in cortical area and towards the medullary canal associated to approximately $1 / 3$ of implant extension. In most cases, in the medullary area, collagen fiber bundles were detected adjacent and oriented parallel to Ti surfaces. Such connective tissue formation exhibited focal areas of mineralized matrix lined by active osteoblasts. The mean percentages of bone-to-implant contact were 2.3 (0.0-7.2 range) for BSP-AK and 0.4 (0.0-1.3 range) for control. Although the Mann-Whitney test did not detect statistically significant differences between groups, these results indicate a trend of BSP-AK treated surfaces to support contact osteogenesis in an experimental model that produces low bone-to-implant contact values.

Key Words: titanium surfaces, implant, bone, calcium-phosphate coating, anodization.

\section{INTRODUCTION}

Titanium (Ti) is the material more frequently used for manufacturing of endosseous implants, due to its excellent biocompatibility (1). Although commercially pure (cp) Ti in its native form is only capable of biomechanical bonding, chemical modifications of cpTi may lead to a bioactive material (1). In order to improve biological, chemical and mechanical properties, surface modifications are often performed including mechanical treatments, thermal spraying, sol-gel, ion implantation, chemical and electrochemical modifications (2).

Among the chemical modifications, deposition of hydroxyapatite (HA) or calcium-phosphate (Ca-P) coatings has been widely used. Such treatments favor the deposition of new Ca-P phases from body fluids directly onto the implant surface, enhancing new bone formation (3). A useful method to obtain a Ca-P enriched surface layer is the anodic spark discharge (ASD) technique (4). The HA produced from hydrothermal treatment after anodization seems to be more stable than plasma sprayed HA. Thus, considering mechanical aspects, hydrothermally-treated anodic $\mathrm{Ti}$ would be a better choice than HA plasma sprayed $\mathrm{Ti}$ (4).

Recently Sandrini et al. (5) developed a novel anodic spark discharge surface treatment, labeled as BSP-AK, that consists of a first anodic spark discharge treatment performed in solution containing $\mathrm{P}$ ions followed by a second treatment in a solution rich in Ca ions, and lastly an alkali etching. The BSP-AK treatment generates tiny fibrillar morphology into the preexisting porous ceramic film by the alkali etching, thus generating an additional level of roughness at the nanoscale level that sustains a complete surface mineralization after

Correspondence: Prof. Dr. Adalberto Luiz Rosa, Departamento de Cirurgia e Traumatologia Buco-Maxilo-Facial e Periodontia, Faculdade de Odontologia de Ribeirão Preto, Universidade de São Paulo, Avenida do Café, s/n, 14040-904 Ribeirão Preto, SP, Brasil. Tel: +55-163602-3980. Fax: +55-16-3633-0999. e-mail: adalrosa@forp.usp.br 
soaking in simulated body fluid $(5,6)$. In vitro evaluations of BSP-AK using cell culture models have demonstrated a significant increase in the proliferation rate of osteoblast-like cells when compared to cpTi, acid etched $\mathrm{Ti}$ and sand-blasted $\mathrm{Ti}$ (5,7-9). Also, an increase in collagen synthesis and alkaline phosphatase activity has been reported (5). Despite these evidences, in vivo evaluations of BSP-AK have not been reported. Therefore, the purpose of this study was to evaluate the bone response to BSP-AK treated Ti after implantation in dog humerus.

\section{MATERIAL AND METHODS}

\section{Titanium Samples}

Cp grade-2 Ti was used to prepare 12 cylinders ( $4.1 \times 12 \mathrm{~mm}$ ). Six cylinders were submitted to the BSPAK technique as described by Sandrini et al. (7) and 6 were left untreated. All samples were rinsed in ultrasonic bath (Branson Automatic Cleaner; Branson Ultrasonic Corp., Danbury, CT, USA) in acetone (RPE, Carlo Erba Reagenti, Milan, Italy) for $10 \mathrm{~min}$ and then in distilled water for $10 \mathrm{~min}$. An electrochemical treatment was considered and performed on Ti samples, consisting of a 2-stage ASD process followed by an alkali etching process (BSP-AK) (5). The first ASD process was performed in a solution containing $\mathrm{P}$ anions and $\mathrm{Ca}$ cations, while the second ASD was performed in a solution containing Ca cations. A variable DC power supply (BVR1200-500-1; Belotti Variatori S.r.l., Milan, Italy) was used to supply power to the circuit. The solution was stirred by magnetic stirring in a refrigerated glass beaker. Electrolytic solution temperature was kept at $0 \pm 2{ }^{\circ} \mathrm{C}$. Ti samples were connected to the anode and a Ti cylindrical shaped net, 50 times bigger than the anodizing sample surface, was used as cathode. Machined Ti samples without electrochemical treatment served as controls. Surfaces were evaluated by scanning electron microscopy (SEM) and energy dispersive X-ray analysis (EDX) (LEO Electron Microscopy Ltd, Cambridge, UK). Prior to implantation, all samples were gamma sterilized in air at a nominal dose of $25 \mathrm{kGy}$ (Gammarad Italia S.p.A., Cà De Fabbri, Italy).

\section{Surgical Procedure}

Two young adult dogs, cross-bred, weighing between 10 and $12 \mathrm{~kg}$ were used. Under general anesthesia, each animal received bilateral implantation of the Ti cylinders in the humerus (three in each humerus), distributed in such way that each animal received implants of the two different groups. The skin and subcutaneous tissue were incised and the anterior area of the humerus was exposed. For installation of the implants, 3 monocortical holes with a final diameter of $4.3 \mathrm{~mm}$ were drilled in each bone at low speed and under abundant saline irrigation, distant $10 \mathrm{~mm}$ one another. Postoperatively, antibiotics and antiinflammatory drugs were administered, repeated 24 and 48 h postoperatively. After 8 weeks, the animals were anesthetized, the bone fragments containing the implants were harvested and euthanasia was performed with a lethal dose of pentobarbital. All procedures were in accordance with the guidelines of the Animal Research Ethics Committee of the University of São Paulo.

\section{Histologic Preparation and Histomorphometry}

After harvesting, the bone segments were cleaned of soft tissue and cut in cubic segments, each one containing one implant. These segments were fixed in buffered $4 \%$ formaldehyde followed by dehydration in a graded series of ethanol (70\%, 90\%, 96\%, and 100\%). Next, segments were embedded in resin (LR White, London, UK), cut and stained according to Maniatopoulos et al. (10). Twenty micrometer-histological sections were analyzed in a Leica DMLB light microscope (Leica, Bensheim, Germany), fitted with a Leica DC 300 F digital camera. Leica Q Win software was used to quantify the bone-to-implant contact (BIC). The acquired digital images with 180 dpi resolution were processed with Adobe Photoshop software (Adobe Systems Incorporated, San Jose, CA, USA).

\section{Statistical Analysis}

As the data had a non-normal distribution, comparisons were performed using Mann-Whitney U- nonparametric test for two independent samples at $\alpha=5 \%$.

\section{RESULTS}

The macroscopic view of the implants clearly revealed differences between Ti surfaces. Machined Ti presented a smoother and brighter surface compared to 
BSP-AK surface (compare Figs. 1A and 1B). The SEM analysis showed that the machined Ti control surface was smooth, with parallel-oriented grooves produced by the machining process (Fig. 1C), while BSP-AK surface exhibited a micron and submicron-scale porosity on remained parallel grooves (Fig. 1D). EDX analysis of machined Ti showed only the presence of Ti (Fig. 2A), while calcium, phosphorous, oxygen and carbon peaks were found on BSP-AK surface in addition to $\mathrm{Ti}$ peaks (Fig. 2B).

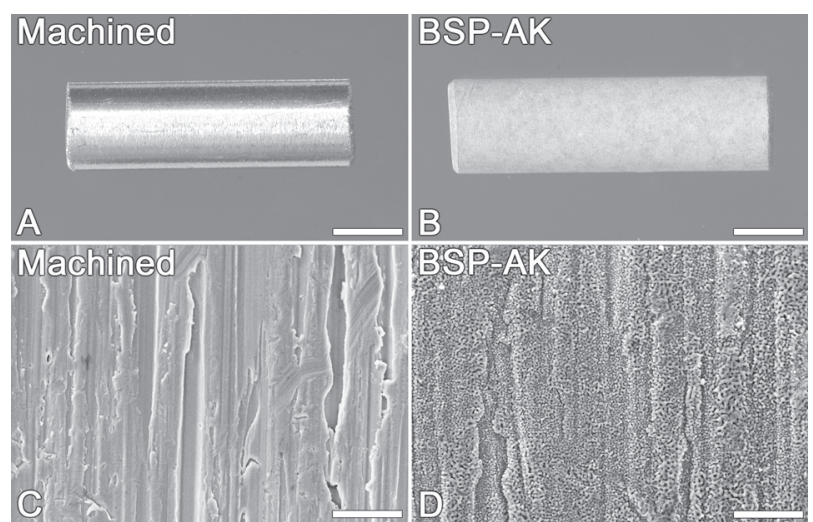

Figure 1. Macroscopic view (A and B) and SEM micrographs (C and D) of machined $\mathrm{Ti}$ and BSP-AK surface. Machined Ti appeared smooth with parallel oriented shallow grooves (C), and BSP-AK surface exhibited a unique surface topography characterized by porosity at the micron-submicron scale on the remaining parallel grooves (D). Bars: A and B $=3 \mathrm{~mm} ; \mathrm{C}$ and $\mathrm{D}=15 \mu \mathrm{m}$.
Low magnification of the ground sections confirmed the correct positioning of all implants. The upper region of the implants established a close contact with the cortical bone, whereas the remaining surface area was totally surrounded by the bone marrow. New bone formation in the cortical bone and towards the medullary canal was associated with approximately one third of the implant extension (Fig. 3A). Higher magnifications at the cortical bone level revealed that a nonmineralized connective tissue was interposed between the material surface and the bone tissue for both groups (Fig. 3B). In the medullary area, a fibrous connective tissue was observed in intimate contact with the implant surface, and was characterized by bundles of collagen fibers parallel to the material surface (Fig. 3C). Such connective tissue exhibited focal areas of mineralized matrix formation. The most relevant difference between the experimental groups was detected in the apical region of the implants, where direct bone apposition took place only for the BSP-AK group (Fig. 3D and $3 \mathrm{E}$ ). For both groups, bone tissue adjacent to the implant surface was lined by cells with typical aspects of active osteoblasts and osteoclasts in Howship's lacunae, indicating the occurrence of bone remodeling. Multinucleated giant cells were occasionally observed in direct contact with the implant surfaces, and were apparently more frequent for the BSP-AK surfaces (Fig. 3F).

The histomorphometric analysis showed low

\section{Machined}

Counts
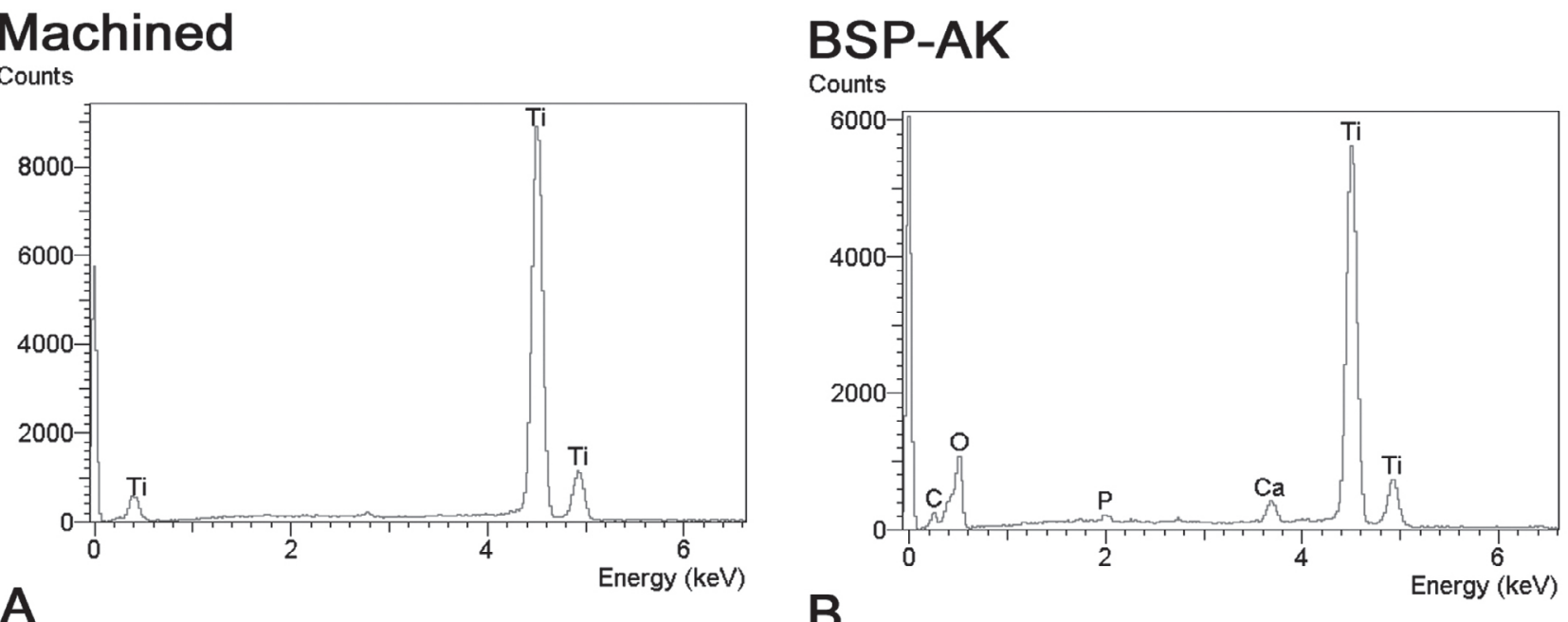

Figure 2. Energy dispersive X-ray analysis of machined (A) and BSP-AK (B) surfaces. On machined Ti (A), only the presence of Ti was detected, while on BSP-AK surface (B) calcium, phosphorous, oxygen and carbon peaks were found in addition to those of Ti. 
percentages of BIC for both groups. The mean percentages of BIC were 2.3 (0.0-7.2 range) for the BSP-AK group and 0.4 (0.0-1.3 range) for the control group. However, such difference was not statistically significant $(\mathrm{p}>0.05)$.

\section{DISCUSSION}

The present study evaluated the bone response to the BSP-AK surface compared to machined Ti cylinders implanted in the anterior region of dog humerus. This model is similar to the rabbit femur model, which allows the evaluation of both the percentage of osseointegration, expressed as BIC in the cortical area, and the percentage of osseoconductivity, expressed as BIC in the medullary area, as described elsewhere (11). However, the present results showed a very low percentage of BIC precluding these observations. It could be due to one or a combination of the following reasons: first, the implants were designed in a cylindrical shape and implanted by pressfit technique; second, the holes were prepared slightly larger than implant diameter (4.3-mm-diameter holes versus 4.1-mm-diameter cylinders), resulting in reduced primary stability; and third, a short time period of observation was chosen (8 weeks).
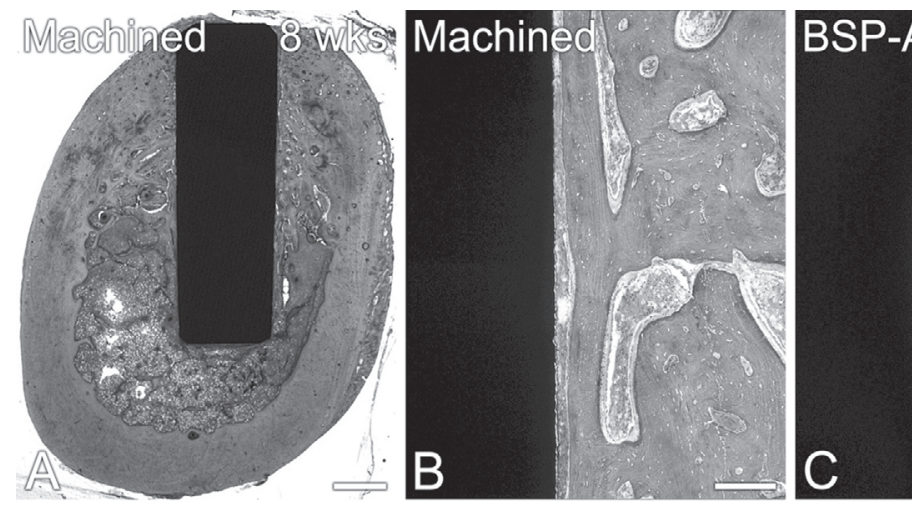

The BSP-AK surface presents a microporous $\mathrm{TiO}_{2}$ layer, rich in calcium and phosphate, with anatase structure $(6,8)$. Accordingly, in the present study, calcium and phosphate were observed on the microporous BSP-AK surface. The stable and small anatase crystalline form of the $\mathrm{TiO}_{2}$ could play a key role for the osseointegration of $\mathrm{Ti}(12,13)$, as it is involved in the in vitro $\mathrm{HA}$ nucleation (14). In addition, the high calcium/phosphate ratio showed by $\mathrm{BSP}-\mathrm{AK}$ surface could mimic a microenvironment similar to that of a bone repair. Considering that osseointegration of $\mathrm{Ti}$ is a complex process that involves the chemical modification of the outer oxide Ti layer (15), the BSPAK treatment could be the basis for the development of a tight intimate bonding formation between metal and bone.

The development of a fibrous connective tissue capsule in direct contact 
with the implant surfaces in the medullary region could be explained by the lack of adequate initial stability of the implants as consequence of the press-fit technique and because the holes were prepared slightly greater than the implant diameter. As pointed out by Maniatopoulos et al. (16), press-fit implants display lower initial stability than threaded implants. Therefore, it is possible that the gap between the cortical bone and implants allowed micromovements beyond those necessary to stimulate an extensive bone formation. In agreement with this, Bidez (17) has estimated that 50 to $100 \mu \mathrm{m}$ of implant micromovement can inhibit bone regeneration.

The fact that higher BIC values could take place at longer periods of evaluation is supported by the observation of lamellar bone lined by osteoid-producing osteoblasts in the cortical area adjacent to the implant surfaces. Also, the fibrous connective tissue in direct contact with the implant at the medullary canal had osteogenic potential, as revealed by the presence of apparently isolated islets of mineralized matrix lined by osteoblasts. In agreement with this, Albrektsson and Johansson (18) have stated that time point is an important parameter to consider. Areas with a low degree of BIC at earlier time points may reach the order of $90 \%$ at the level of the cortical bone after 1 year of follow-up.

Although it has been demonstrated that higher levels of bone formation take place in the apical portion of Ti implants even inside the medullary canal (19), this is particularly true for bioactive biomaterials, but not for bioinert ones (11). Considering that only BSP-AK implants supported bone formation associated with the apical portion of their structure, it could be suggested that such surface treatment results in a more bioactive Ti surface compared to the untreated Ti. Additionally to the chemical modification, alterations on surface morphology produced by BSP-AK treatment may have favored bone formation on BSP-AK implants, as it has been reported a correlation between surface topography and the extent of bone-implant interface (20).

In conclusion, neither microscopic observation nor histomorphometric analysis indicated marked differences between the control, machined Ti and the BSPAK treated $\mathrm{Ti}$, although a tendency for the latter to support contact osteogenesis was noticed. Further studies are necessary to evaluate the bone response to BSP-AK surface modification by using self-tapping screw Ti implants in order to overcome the limitations of the present study.

\section{RESUMO}

O objetivo desse estudo foi avaliar a resposta do tecido ósseo à superfície de titânio (Ti) enriquecida com $\mathrm{Ca}$ e $\mathrm{P}$ obtida por anodização (BSP-AK). Três cilindros de Ti (4,1 x $12 \mathrm{~mm}$ ) BSPAK ou usinado (controle) foram implantados bilateralmente nos úmeros de dois cães de raça indefinida. Oito semanas após a implantação, os fragmentos ósseos contendo os implantes foram removidos e processados para análises histológica e histomorfométrica. A formação óssea foi observada na região cortical e no canal medular até aproximadamente um terço da extensão do implante. Na maioria dos casos, feixes de fibras colágenas dispostos paralelamente à superfície do implante foram observados na região medular. Nessa região observaram-se também áreas focais de formação de matriz mineralizada e osteoblastos ativos. Os implantes do grupo BSP-AK apresentaram média de contato osso-implante $2,3 \%$, com medidas variando de 0,0 a $7,2 \%$ e os do grupo controle tiveram média $0,4 \%$, com medidas variando de 0,0 a $1,3 \%$. Apesar do teste de MannWhitney não mostrar diferença estatisticamente significante entre os grupos, nossos resultados indicaram uma tendência para a ocorrência de osteogênese de contato na superfície BSP-AK em um modelo experimental que resulta em baixos valores de contato osso-implante.

\section{ACKNOWLEDGEMENTS}

This work was supported by a grant from FAPESP (Master's fellowship granted to Rosemeire de Lordo Franco; Process \#2004/ 05284-8). We would like to express a particular thank to Sebastião Carlos Bianco for technical assistance during the animal surgeries and for the preparation of the ground sections.

\section{REFERENCES}

1. Albrektsson $\mathrm{T}$, Wennerberg A. Oral implant surfaces: part 1 review focusing on topographic and chemical properties of different surfaces and in vivo responses to them. Int $\mathbf{J}$ Prosthodont 2004;17:536-543.

2. Schuler M, Trentin D, Textor M, Tosatti SG. Biomedical interfaces: titanium surface technology for implants and cell carriers. Nanomed 2006;1:449-463.

3. Puleo DA, Nanci A. Understanding and controlling the bone implant interface. Biomaterials 1999;20:2311-2321.

4. Yao C, Webster TJ. Anodization: a promising nano-modification technique of titanium implants for orthopedic applications. J Nanosci Nanotech 2006;6:2682-2692.

5. Sandrini E, Chiesa R, Rondelli G, Santin M, Cigada A. A novel biomimetic treatment for an improved osteointegration of titanium. J Appl Biomat Biomech 2003;1:33-42.

6. Sandrini E, Morris C, Chiesa R, Cigada A, Santin M. In vitro assessment of the osteointegrative potential of a novel multiphase anodic spark deposition coating for orthopaedic and dental implants. J Biomed Mater Res 2005;73B:392-399.

7. Giordano C, Sandrini E, Del Curto B, Signorelli E, Rondelli G, Di Silvio L. Titanium for osteointegration: comparison between a novel biomimetic treatment and commercially exploited surfaces. J Appl Biomat Biomech 2004;2:35-44.

8. Giordano C, Chiesa R, Sandrini E, Cigada A, Giavaresi G, Fini 
M. et al.. Physical and biological characterizations of a novel multiphase anodic spark deposition coating to enhance implant osseointegration. J Mater Sci Mater Med 2005;16:12211229.

9. Franco RL, Chiesa R, Beloti MM, De Oliveira PT, Rosa AL. Human osteoblastic cell response to a $\mathrm{Ca}$ - and P-enriched titanium surface obtained by anodization. J Biomed Mater Res A. 2008. In press.

10. Maniatopolous C, Rodriguez A, Deporter DA, Melcher AH. An improved method for preparing histological sections of metallic implants. Int $\mathbf{J}$ Oral Maxillofac Implants 1986;1:3137.

11. Rosa AL, Beloti MM, De Oliveira PT, Van Noort R. Osseointegration and osseocondutivity of hydroxyapatite of different microporosities. J Mater Sci Mater Med 2002;13:1071-1075.

12. Giavaresi G, Ambrosio L, Battiston GA, Casellato U, Gerbasi R, Finia M. et al.. Histomorphometric, ultrastructural and microhardness evaluation of the osseointegration of a nanostructured titanium oxide coating by metal-organic chemical vapour deposition: an in vivo study. Biomaterials 2004;25:5583-5591

13. Kokubo T, Kushitani H, Sakka S, Kitsugi T, Yamamuro T. Solutions able to reproduce in vivo surface-structure changes in bioactive glass-ceramic A-W. J Biomed Mater Res 1990;24:721-734.
14. Wang XX, Hayakawa S, Tsuru K, Osaka A. Improvement of bioactivity of $\mathrm{H}(2) \mathrm{O}(2) / \mathrm{TaCl}(5)$-treated titanium after subsequent heat treatments. J Biomed Mater Res 2000;52:171176 .

15. Textor M, Sitting C, Frauchiger V, Tosatti S, Brunette D. Properties and biological significance of natural oxide films on titanium and its alloys. Titanium Med 2001;7:171-224.

16. Maniatopoulos C, Pilliar RM, Smith DC. Threaded versus porous-surfaced designs for implant stabilization in boneendodontic implant model. J Biomed Mater Res 1986;20:1309-1333.

17. Bidez MW. The threshold of micromotion conductive to bone ingrowth, Int J Oral Implantol 1991;8:113-115.

18. Albrektsson T, Johansson J. Quantified bone tissue reactions to various metallic materials with reference to the so-called osseointegration concept. In: The Bone Biomaterial Interface, II volume Davies JE and Albrektsson T (Editors). University of Toronto Press: Toronto; 1996. p 357-363.

19. Berglundh T, Abrahamsson I, Lang NP, Lindhe J. De novo alveolar bone formation adjacent to endosseous implants. Clin Oral Implants Res 2003;14:251-262.

20. Buser D, Schenk RK, Steinemann S, Fiorellini JP, Fox CH, Stich H. Influence of surface characteristics on bone integration of titanium implants. A histomorphometric study in miniature pigs. J Biomed Mater Res 1991;25:889-902.

Accepted February 28, 2008 